www.jmscr.igmpublication.org

Impact Factor 5.244

Index Copernicus Value: 83.27

ISSN (e)-2347-176x ISSN (p) 2455-0450

crossref DOI:_http://dx.doi.org/10.18535/jmscr/v4i9.78

Journal Of Medical Science And Clinical Research

\title{
Metstatic and Mortality Pattern in Carcinoma of Breast Patients in Tertiary Health Care Centre
}

\author{
Authors \\ Neelesh Shrivastava ${ }^{1}$, Dr Rachana Gupta ${ }^{2}$, Dr A.P.S.Gaharwar ${ }^{3}$, Dr Yogesh Kailasiya ${ }^{4}$ \\ ${ }^{1}$ Sr. Resident, Dept of Surgery, S.S. Medical College, Awadesh Pratap Singh University, Rewa \\ ${ }^{2}$ Associate Professor, Dept of Surgery, S.S. Medical College, Awadesh Pratap Singh University, Rewa \\ ${ }^{3}$ Professor \& HOD, Dept of Surgery, S.S. Medical College, Awadesh Pratap Singh University, Rewa \\ ${ }^{4}$ Assistance Professor, Dept of Surgery, S.S. Medical College, Awadesh Pratap Singh University, Rewa \\ Corresponding Author \\ Neelesh Shrivastava
}

Sr. Resident, Department of Surgery, S.S. Medical College, Awadesh Pratap Singh University, Rewa

Email: namita1.shrivastava@gmail.com

\begin{abstract}
Introduction: carcinoma breast is second common cancer after Carcinoma cervix in India. Globally, it accounts for $25 \%$ of female cancers and $18 \%$ of death from cancer in women ${ }^{1}$. Previous studies were shows high incidence of breast cancer and cancer related mortality among post menopausal females in India. This study to find out metastatic and mortality pattern in breast cancer patient which was not carried out in this part of country.
\end{abstract}

Material and methods: this is a prospective analysis (2013-2014) of database from all surgical units of S.S. Medical College, Rewa, India.

Result: The incidence of carcinoma of breast was 25.83\%, amongst the total admitted cancer patients. Peak incidence $31.4 \%$ was in the age range $41-50$ years, with the mean age of 45.2 years. All patients were females and (98.5\%) were married. $67.1 \%$ patients were from rural area and $32.8 \%$ were from urban area. most of the patients were illiterate 50(71.4\%) while 20(28.5\%) patients were literate. Out of 70 patients, 12 patients had metastatic lesion. Secondary's in lung account for $75 \%$ of metastatic lesion and $12.8 \%$ of total ca breast patients followed by secondary's in liver account for $33.3 \%$ of metastatic lesion and $5.7 \%$ of total ca breast patients. Lymph oedema of arm was $16.6 \%$ of metastatic lesion and $2.8 \%$ of total ca breast patients. Skeletal metastasis was present only in one patient. Mortality was $5.71 \%$.i.e 4 patients of carcinoma of breast who present in stage IV and were having malignant pleural effusion and/ or multiple liver metastasis and/ or lymph oedema of arm.

Conclusion: It is concluded from this study that factors associated with increase in mortality were old age, female gender, and illiteracy, and marital status, presence of distant metastasis and late stage of disease. For reducing the mortality due to breast cancer early screening and proper education to high risk and unaware population is needed.

Keywords: Breast carcinoma, Mortality, Female, Metastasis.

\section{INTRODUCTION}

Carcinoma of the breast is one of the most common cancer affecting women worldwide. It is second common cancer after Carcinoma cervix in India. Globally, it accounts for $25 \%$ of female cancers and $18 \%$ of death from cancer in women ${ }^{1}$. 
The incidence, clinical presentation and survival rates vary in different geographic areas and among different races and ethnic communities within the same geographic region ${ }^{2}$.Higher incidence and lower mortality rates have been reported from developed countries, whereas lower incidence of breast cancer $(45 \%$ of all cases reported worldwide) and higher mortality (55\% of all cancer related deaths worldwide) occurring in the developing and underdeveloped countries. Late stage presentation of biologically aggressive disease in relatively younger population is the characteristic feature reported from these countries. International variations in outcome of breast cancer are related to early diagnosis and prompt and complete treatment ${ }^{2}$. The early presentation of cancer breast is due to increased awareness in developed countries and urban areas. Increasing the facility of adequate therapy offers hope for reduction in morbidity and mortality due to carcinoma breast.

\section{MATERIAL AND METHOD}

Study design-: It is an observational, prospective hospital based study in Department of Surgery; from $1^{\text {st }}$ August 2013 to $31^{\text {st }}$ July 2014.A total 70 patients of breast cancer admitted during study period. Various epidemiological information such as age, sex, axillary lymph node involved, histological type, type of surgery, type of chemotherapy, hospital stay and morbidity, and type of metastasis according to stage and causes of death were noted from hospital records.

\section{RESULT}

Age -

The age of patients ranged from 28years (youngest) to 85 years (eldest), with mean age of 45.2 years. Peak incidence $31.4 \%$ was in the age range 41-50 years for breast cancer. In the age group 51-60 years, 3 patients died (75\%). The second age group was 61-70 years, which account for 1 patient (25\%). Patient below 40 years rarely has mortality.(table no.-1)
Table no.-1 Age wise distribution of breast carcinoma

\begin{tabular}{|c|c|c|c|}
\hline S.no & $\begin{array}{l}\text { Age } \\
\text { (in years) }\end{array}$ & No. of cases & Percentage \\
\hline 1. & $21-30$ & 2 & $2.8 \%$ \\
\hline 2. & $31-40$ & 16 & $22.8 \%$ \\
\hline 3. & 41-50 & 22 & $31.4 \%$ \\
\hline 4. & $51-60$ & 16 & $22.8 \%$ \\
\hline 5. & $61-70$ & 11 & $15.7 \%$ \\
\hline 6. & $71-80$ & 2 & $2.8 \%$ \\
\hline 7. & $81-90$ & 1 & $1.4 \%$ \\
\hline \multicolumn{2}{|c|}{ TOTAL } & 70 & $100 \%$ \\
\hline
\end{tabular}

\section{Sex-}

All patients were female who developed subsequent metastasis and death. Female predominance found throughout study. No male patients were record

\section{Marital status and residence}

Out of 70 patients 69 (98.5\%) were married. One patient was unmarried female patient (aged $80 \mathrm{yr}$ ), accounting for $1.4 \%$ of total cases. Residences have more rural predominance. Most of the patients $(67.1 \%)$ were from rural area and $32.8 \%$ were from urban area.

\section{Presenting complaint and associated complaint}

Lump in breast was the predominant symptom in all patients and out of them two had a past history of recurrent lump in breast. Breast lump was painful in $38(54.2 \%)$ patients. Ipsilateral axillary swelling in $35(50 \%)$ patients. An ulcer on the breast was present in $7(10 \%)$ patients. There were $6(8.5 \%)$ patients with nipple discharge. Among other associated symptoms weakness was commonest and seen in 58(82.8\%) patients, anorexia in $38(54.2 \%)$ patients and weight loss in $30(42.8 \%)$ patients. (Table no-2)

Table no.-2 Incidence according to presenting complaints, $\mathrm{n}=70$

\begin{tabular}{|l|l|l|l|}
\hline $\begin{array}{l}\text { S. } \\
\text { No. }\end{array}$ & $\begin{array}{l}\text { Presenting } \\
\text { Complaints }\end{array}$ & $\begin{array}{l}\text { No. of } \\
\text { Patients }\end{array}$ & Percentage \\
\hline 1. & Lump in breast & $\mathbf{7 0}$ & $\mathbf{1 0 0 \%}$ \\
\hline 2. & Painfull lump & 38 & $54.2 \%$ \\
\hline 3. & Axillary swelling & 35 & $50 \%$ \\
\hline 4. & Ulcer on breast & 07 & $10 \%$ \\
\hline 5. & Discharge from nipple & 06 & $8.5 \%$ \\
\hline
\end{tabular}




\section{Stage}

Clinical staging of the extent of disease was done using the Manchester classification. Most of the patients of carcinoma breast presented in stage II $32(45.7 \%)$ followed by $23(32.8 \%)$ in stage III, 12 $(17.1 \%)$ patients presented with stage IV diseases while only three $(4.2 \%)$ patients in stage I disease. (Table no.-3)

Table no.-3 Incidence according to clinical stage of malignancy

\begin{tabular}{|c|c|c|c|}
\hline S. No. & Stage & $\begin{array}{ll}\text { No. } & \text { Of } \\
\text { Cases }\end{array}$ & Percentage \\
\hline 1. & I & 3 & $4.2 \%$ \\
\hline 2. & II & 32 & $45.7 \%$ \\
\hline 5. & III & 23 & $32.8 \%$ \\
\hline 6. & IV & 12 & $17.1 \%$ \\
\hline & ГOTAL & 70 & $100 \%$ \\
\hline
\end{tabular}

\section{Histo-pathological type}

Histopathology examination of the specimen was done in 70 patients. Infiltrating ductal carcinoma was the most common type of carcinoma accountting for $74.2 \%$ patients followed by ductal carcinoma in situ in $25.7 \%$ patients.(Table no.-4)

Table no 4 Distribution according to histopathology reports, $n=70$

\begin{tabular}{|l|l|l|l|}
\hline S.No & Finding & $\begin{array}{l}\text { No. of } \\
\text { Cases }\end{array}$ & \% \\
\hline 1. & Infiltrating ductal carcinoma & $\mathbf{5 2}$ & $\mathbf{7 4 . 2 \%}$ \\
\hline 2. & Ductal carcinoma in situ & 18 & $25.7 \%$ \\
\hline \multicolumn{2}{|c|}{ TOTAL } & 70 & 100 \\
\hline
\end{tabular}

\section{Hospital stay and mortality}

Duration of hospital stay was 6 to 10 days in 26 (37.1\%) patients followed by $>15$ days in 20 patients (28.5\%) (Graphno.6). Mortality was $5.71 \%$. i.e 4 patients of carcinoma of breast who present in stage IV and were having malignant pleural effusion and/ or multiple liver metastasis and/ or lymph oedema of arm (table no.5 and Table no.6)

Table no-5 Mortality among breast carcinoma patients

\begin{tabular}{|l|l|c|c|}
\hline S.No. & Total No. breast & \multicolumn{2}{|c|}{ Death } \\
\cline { 3 - 4 } & Cancer Pts & Patients & Percentage \\
\hline 1 & $\mathbf{7 0}$ & 4 & $5.71 \%$ \\
\hline
\end{tabular}

Table no-6 Distribution according to duration of hospital stay

\begin{tabular}{|c|c|c|c|}
\hline S.No. & Hospital Stay & $\begin{array}{l}\text { No. Of } \\
\text { Patients }\end{array}$ & Percentage \\
\hline 1. & $0-5$ & 18 & $25.7 \%$ \\
\hline 2. & 6-10 & 26 & $37.1 \%$ \\
\hline 3. & $11-15$ & 6 & $8.5 \%$ \\
\hline 4. & $>15$ & 20 & $28.5 \%$ \\
\hline & TOTAL & 70 & 100.0 \\
\hline
\end{tabular}

\section{Secondary Metastasis}

Out of 70 patients, 12 patients had metastatic lesion. Secondary's in lung account for $75 \%$ of metastatic lesion and $12.8 \%$ of total ca breast patients followed by secondary's in liver account for $33.3 \%$ of metastatic lesion and $5.7 \%$ of total ca breast patients. Lymph edema of arm was $16.6 \%$ of metastatic lesion and $2.8 \%$ of total ca breast patients. Skeletal metastasis was present only in one patient (table no.7).

Table no.7 Distribution according to Incidence of metastatic lesion, $\mathrm{n}=70$

\begin{tabular}{|l|l|c|c|c|}
\hline S.No. & Complications & $\begin{array}{c}\text { No. of } \\
\text { Cases } \\
\text { n=12 }\end{array}$ & $\begin{array}{c}\text { Percentage } \\
\text { Among stage } \\
\text { IV patients }\end{array}$ & $\begin{array}{c}\text { Percentage } \\
\text { Among all } \\
\text { Ca breast pt. }\end{array}$ \\
\hline 1. & $\begin{array}{l}\text { Secondary's } \\
\text { in Lungs }\end{array}$ & $\mathbf{9}$ & $\mathbf{7 5 \%}$ & $\mathbf{1 2 . 8 \%}$ \\
\hline 2. & $\begin{array}{l}\text { Secondary's in } \\
\text { Liver }\end{array}$ & 4 & $33.3 \%$ & $5.7 \%$ \\
\hline 3. & $\begin{array}{l}\text { Lymph edema } \\
\text { of arm }\end{array}$ & 2 & $16.6 \%$ & $2.8 \%$ \\
\hline 4. & $\begin{array}{l}\text { skeletal } \\
\text { metastasis }\end{array}$ & 1 & $8.3 \%$ & $1.4 \%$ \\
\hline
\end{tabular}

\section{Cause of mortality-}

Out of 70 patients, 4 were died .Main cause of death was due to pulmonary complication, 3 out of 4 patients, pleural effusion and pulmonary metastasis and associated pneumonitis. One patient $(25 \%)$ was died due to liver metastasis and associated liver failure. Mortality was significantly associated with age, sex, stage of disease, type of histology, secondary metastasis and adjuvant chemotherapy.

\section{DISCUSSION}

Mortality rates from breast cancer have increased during the past 60 years in every country. International variation in both incidence and 
mortality is one of the most striking features of breast cancer.

Rewa is the major city of Vindhya region with a population of 15.54lacs (1991 census). It is situated in the north eastern corner of the state of Madhya Pradesh, India. It is the main educational and medical centre in this region. With an increasing population, the number of breast cancer cases is on the rise in Rewa.

Age is one of the important epidemiological determinants of breast cancer mortality. In the present study mean age of incidence of carcinoma breast was 45.2 years. The incidence of carcinoma breast was found to be highest in age group 41$50 \mathrm{yr}$ (31.4\%) next common group was 31-40 yr and 51-6 yr constitutes $22.8 \%$ each which is comparable from other authors study eg. M.N. Okobia et $\mathrm{al}^{1}$ (2001) reported mean age as 38 years, Hafiz M.Aslam ${ }^{3}$ (2011) reported mean age 45.66 years, Samina et $\mathrm{al}^{2}$ (2012) reported mean age 47 years. In Asia, breast cancer incidence peaks among women in their forties, whereas in United State and Europe, it peaks among women in their sixties. The main age group associated with metastasis and mortality was between 51-60 years. This reason for this age presentation that patient after surgical treatment were unaware for their follow up or may not taking complete treatment like radiation or hormonal therapy and present late in their 60s with metastasis and near to death.

In this study majority $(67.1 \%)$ of patients from the rural area.

Married women found commonly affected $(98.5 \%)$ and $1.4 \%$ was unmarried. Other authors have slight higher incidence of unmarried women in world to be affected by carcinoma breast. It is evident that parity plays a much bigger role than marital status of a female patient in development of breast cancer. In Indian scenario, marriage of a female is a social enforcement and therefore in our study $98.5 \%$ patients were married.

Presenting symptoms are more predictors of stage and near to metastasis and mortality. In present study $100 \%$ of patients presented with lump of varying duration. $54.2 \%$ patients had painful lump, the increase number of cases of painful lump is explained by the fact that in this region due to ignorance, poverty, carelessness and fear. The lumps in breast are often ignored and patients seek advice when the mass either increased in size suddenly or has become painful due to massage, hot fomentation or application of local ointment and/ or hemorrhage, superseding infection, secondary changes in the lump. According to $\mathrm{M}$. N. Okoiba et $\mathrm{al}^{1}$ (2001), Most of the tumours were initially painless and patients were likely to disregard these lesions as a result of ignorance. In addition, most patients were likely to seek treatment from traditional healers, patent medicine stores and spiritual homes and only presented to hospital when treatment in these centres had failed. Reports from our hospital suggest that low socioeconomic status, poverty and ignorance are the major factors responsible for this.

Stage of disease well correlated with morbidity and metastasis. In our study patients who died of breast cancer metastasis were in stage IV. In present series, Most of the patients of carcinoma breast presented in stage II 32(45.7\%) followed by $23(32.8 \%)$ in stage III, $12(17.1 \%)$ patients presented with stage IV diseases while only three (4.2\%) patients in stage I disease. According to Samina et $\mathrm{al}^{2}$ (2012), The striking difference in the stage distribution of breast cancer patients in the developing and developed countries has been largely attributed to the lack of screening facilities, delays in seeking medical attention, poor socioeconomic status, poor health care systems and poor diagnostic and therapeutic facilities in developing countries.

In the present series, histopathology reports shows, infiltrating ductal carcinoma was the most common type of carcinoma accounting for $74.2 \%$, which is comparable with other authors eg. Kaushik Saha et $\mathrm{al}^{6}$, M.N.Okobia et $\mathrm{al}^{1}$ (2001), N.A.S. $\operatorname{Alwan}^{7}$ (2010) study.

In our study out of 70 patients, chemotherapy was given in $50(71.42 \%)$ patients.48 patients received adjuvant chemotherapy and 2 patients received neo adjuvant chemotherapy. All patients received $\mathrm{CMF}$ regime. There are recent 3 prospective 
randomized trials available that have shown that CAF regime is $14 \%$ superior to $\mathrm{CMF}$ regime; however the patients in our study received CMF regime. Some authors study comparable with our study, M.N.Okobia ${ }^{1}$ et al (2001): in his study given chemotherapy in $71.42 \%$ patients with CMF regime. L.M.D.Yusufu ${ }^{8}$ et al (2003): in his study given chemotherapy in $77.4 \%$ patients with $\mathrm{CMF}$ regime.

Tamoxifen was given to all the patients who were peri-menopausal women.

In our study, Out of 70 patients, $12(17.14 \%)$ patients had metastatic lesion. Secondary's in lung account for $75 \%$ (9 of 12) of metastatic lesion followed by secondary's in liver account for $33.3 \%$ (4 of 12) of metastatic lesion. Lymph edema of arm was $16.6 \%$ ( 2 of 12) of metastatic lesion. Skeletal metastasis was present only in one patient. This suggestive that significant number of cases present in late stage of disease. In our study, mortality was $5.71 \%$.i.e 4 patients of carcinoma of breast who present in stage IV and were having malignant pleural effusion and/ or multiple liver metastasis and/ or lymph edema of arm. M.N.Okobia ${ }^{1}$ et al (2001) in his study reported mortality was $20.7 \%$ with 5 year survival about $8.7 \%$.

\section{CONCLUSION}

It is concluded from the study that majority of patients died because of lack of knowledge and awareness after the primary treatment or for the primary disease. they present to clinics when they got symptoms due primary disease or metastasis. We have to increase awareness around the population for the primary breast cancer and patient who got treatment should be encouraged for proper followed up to detect recurrence in early time. Most patients have mortality due to metastasis in other organs especially in lung and liver. Patient should be treated palliative in metastatic case and made pain free to him by as much as interventions.

\section{REFRENCES}

1. MN Okobia and U Osime. Clinicopathological study of Carcinoma of the Breast in Benin City. Dept of Surgery, College of Medical Science, University of Benin Teaching Hospitals Benin City Nigeria. African Journal of Reproductive Health. page 57-62.

2. Samina Khokher, Muhammad Usman Qureshi, Masooma Riaz, Naseem Akhtar, Afaf Saleem, Clinicopathologic Profile of Breast Cancer Patients in Pakistan: Ten Years Data of a Local Cancer Hospital, (2012)

3. Hafiz Muhammad Aslam; clinicopathological profile of patients with breast disease, Aslam et al, diagnostic pathology 2012.

4. B. Mcn. Truscott. Carcinoma of The Breast. An Analysis OfThe Symptoms, Factors Affecting Prognosis, Results Of Treatment And Recurrences In 1211 Cases Treated At The Middlesex Hospital.From the Middlesex Hospital, London, W.I. Received for publication March 25, 1947.

5. W. L. Harnett., Statistical Report On 2529 Cases Of Cancerof The Breast.Published for the Clinical Cancer Research Committee ofthe British Empire Cancer Campaign. Received for publication July 16, 1948

6. Kaushik Saha, Gargi Raychaudhuri, Bitan Kumar Chattopadhyay. Clinico-pathological study of breast carcinoma: A prospective two year study in a tertiary care hospital. Clinical Cancer Investigation Journal 2013;2(1):34-40.

7. N.A.S. Alwan, breast cancer, demographic characteristic and clinic pathological presentation of patients in Iraq, EMHJ VOL.16,2010.

8. L.M.D. Yusufu,V.I.Odigie and A Mohammad, Breast Mass In Zaria, Nigeria, Annals of African medicine ,vol.2,2003 